\title{
COMPLEXIDADES DA RESPONSABILIDADE SOCIAL EMPRESARIAL NO BRASIL: TERCEIRIZAÇÃO E GESTÃ̃ PARTICIPATIVA
}

\author{
Roberto Patrus \\ Doutor em Filosofia pela Universidad Complutense de Madrid - UCM \\ Professor do Programa de Pós-Graduação em Adminstração - PPGA/PUC Minas \\ robertopatrus@pucminas.br \\ Betania Tanure \\ Doutora em Administração pela Brunel University - B.U. \\ Professora do Doutorado e Mestrado em Administração da PUC Minas \\ betaniatanure@pucminas.br \\ Antonio Carvalho Neto \\ Professor do Doutorado e Mestrado em Administração da PUC Minas \\ Professor do Programa de Pós-Graduação em Adminstração - PPGA/PUC Minas \\ carvalhoneto@pucminas.br \\ Joyce Osland \\ Professor at College of Business San José State University \\ osland_j@cob.sjsu.edu \\ Abbjorn O sland \\ Professor at College of Business San José State University \\ osland_a@cob.sjsu.edu \\ Caroline Carpenedo \\ caroline.carpenedo@gmail.com
}

RESUMO

Este artigo ocupa-se de duas questões originadas de pesquisas sobre a responsabilidade social com os empregados. A primeira: Maiores níveis de gestão participativa na empresa enfraquecem as relações dos empregados com os sindicatos, como argumentam Heckscher (1996), Zibas (1997) e Tuma (1999)? A segunda: Como estabelecer responsabilidade social nas políticas de recursos humanos com terceirizados sem gerar risco de passivo trabalhista, considerando a legislação brasileira? Foram analisados os resultados de pesquisas exploratórias realizadas por meio de estudos de caso por um grupo de pesquisa de um Programa de Pós-Graduação em Administração. Trata-se, portanto, de análise de dados secundários. A estratégia de pesquisa adotada foi de natureza qualitativa, de caráter descritivo. A análise dos dados permitiu responder que existe relação entre a avançada gestão participativa, como percebida pelos empregados, e a fraca relação da empresa com o sindicato de trabalhadores, mas apenas quando se trata de empregados que recebem altos salários e apenas nas empresas de serviços. Com relação à segunda questão norteadora deste artigo, observa-se que para haver relação de emprego é necessário haver os quatro requisitos impostos pela legislação: pessoalidade, subordinação, não-eventualidade e onerosidade. Quando a empresa oferece ao terceirizado os mesmos benefícios e condições de trabalho que oferece para seus empregados, ela corre o risco de ter estabelecido com o terceirizado um vínculo de emprego, o que aumenta o risco de passivo trabalhista da organização que terceirizou.

Palavra-chave: Gestão participativa; Responsabilidade social empresarial; Terceirização.

\section{COMPLEXITIES OF CORPORATE SOCIAL RESPONSIBILITY IN BRAZIL: OUTSOURCING AND PARTICIPATORY MANAGEMENT}

\begin{abstract}
This article deals with two issues arising from our research on corporate social responsibility to employees. The first: do higher levels of participative management in the enterprise weaken relations with employee unions, as argued by Heckscher (1996), Zibas (1997) and Tuma (1999)? The second: how is a social responsibility established in human resources policies with contractors without creating risk of labor liabilities, considering the Brazilian legislation? We analyzed the results of exploratory research carried out by means of case studies by a research group of a PostGraduation Program in Management. The research strategy adopted was secondary data analysis, qualitative, and descriptive. The data analysis allowed us conclude that there is a relationship between advanced participative management, as perceived by employees, and the company's poor relationship with the union workers, but only when it comes to employees receiving high salaries and only in service firms. Regarding the second research question of this article, we observe that, for any relation of employment, there must be four requirements imposed by legislation: personhood, subordination, non-eventuality, and not charging. When the company offers outsourcing with the same benefits and working conditions they offer to their employees, it runs the risk of establishing an employment contract with the outsourced jobs, which increases the risk of liability of that outsourced labor organization. The risk of labor liabilities is indeed real, according to the data of our investigation.
\end{abstract}

Keyword: Corporate Social Responsibility; Participatory Management; Outsourcing. 


\section{INTRODUÇÃO}

Este artigo procura investigar duas questões relacionadas com a responsabilidade social da empresa (RSE) com seus trabalhadores:

1) Maiores níveis de gestão participativa na empresa enfraquecem as relações dos empregados com os sindicatos?

2) Como estabelecer responsabilidade social nas políticas de recursos humanos com terceirizados sem gerar risco de passivo trabalhista, considerando a legislação brasileira?

As duas perguntas nasceram de pesquisas exploratórias realizadas pelo grupo de pesquisa do qual os autores desse artigo fazem parte. A primeira, encontra respaldo na tese gerencialista de Heckscher (1996), corroborado por Zibas (1997) e Tuma (1999). A segunda questão problematiza a relação entre responsabilidade social e terceirização. De acordo com o discurso da RSE, difundido, principalmente pelo Instituto Ethos, a empresa deve oferecer ao empregado terceirizado os mesmos benefícios e condições de trabalho que são oferecidos aos trabalhadores diretos. Entretanto, se a empresa oferece aos seus terceirizados as mesmas condições de trabalho e benefícios que oferece aos seus empregados, ela estará desrespeitando a legislação trabalhista e criando um risco de passivo trabalhista. Nossas pesquisas mostram que este risco é real. Gerentes e empregados presenciam muitas situações em que o vínculo com o terceirizado assume caráter de pessoalidade e subordinação quando se procura equiparar as condições de trabalho entre terceirizados e trabalhadores diretos.

A associação entre a Responsabilidade Social Empresarial (RSE) e os stakeholders da empresa (Clarkson, 1995; Frederick, 1994; 1998) leva muitos pesquisadores a priorizar um desses públicos para realizar as suas pesquisas. Tal limitação faz-se necessária, por um lado, pelas limitações de recursos e de tempo para a realização das investigações. Desde 2003, o Núcleo de Pesquisas do qual os autores deste artigo pertencem, optou por focar suas investigações, prioritariamente, no âmbito dos empregados de empresas nacionais e multinacionais que operam no Brasil (Patrus-Pena et al., 2004; Coelho, 2004; Patrus-Pena \& Oliveira, 2005; Furtado, 2006; Patrus-Pena et al., 2007; Santos, 2007; Mattoni, 2007; Nagli, 2008; Pereira, 2008; Napoleão, 2007). $\mathrm{O}$ foco no trabalhador se deve à reconhecida importância desse stakeholder (Arruda \& Navran, 2000; Wood, 1991).

Todas essas pesquisas foram caracterizadas como exploratórias, ou seja, pesquisas cujo campo de conhecimento ainda é novo e não permite a formulação de hipóteses. Em geral, as pesquisas realizadas foram estudos de caso único ou estudos de caso comparativo entre não mais do que duas empresas. Ao todo, o grupo de pesquisa estudou 12 diferentes empresas. Isoladamente, cada estudo de caso não acrescenta muito para o desenvolvimento científico, no sentido de formular leis e generalizações. Em conjunto, entretanto, as diferentes pesquisas podem compor um tecido maior, que se articula por meio do diálogo entre pesquisadores e o uso dos resultados das pesquisas anteriores nas pesquisas em andamento. A maior limitação de um estudo de caso - a dificuldade de generalização dos resultados obtidos - pode, assim, ser minimizada pelo diálogo entre os pesquisadores e a contínua atualização do estado da arte da pesquisa no campo da responsabilidade social com os trabalhadores. Trata-se, de fato, de uma construção coletiva.

Buscamos sistematizar o estado da arte da pesquisa sobre Responsabilidade Social Empresarial com o público interno no Brasil. Todos os estudos de caso anteriormente citados fizeram análises de diferentes grupos de variáveis relacionadas a recursos humanos e relações de trabalho, tais como relações com sindicatos, gestão participativa; relações com trabalhadores terceirizados; valorização da diversidade; política de remuneração, benefícios e carreira; cuidados com a saúde, segurança e condições de trabalho; compromisso com o desenvolvimento profissional e a empregabilidade; comportamento frente a demissões; preparação para a aposentadoria. Constata-se que pesquisas que buscam relacionar a RSE com o Gestão de Pessoas são ainda limitadas (Wehling et al., 2009) - lacuna que este artigo pretende contribuir. 
Todos esses estudos de caso, com apoio de dados significativos, sugerem desafios e complexidades da RSE com os empregados no Brasil (Patrus-Pena et al, 2004; Oliveira, 2005; Furtado, 2006; França, 2005; Santos, 2007; Mattoni, 2007; Nagli, 2008; Pereira, 2008; Furtado \& Patrus-Pena, 2007; Coelho, 2004; Napoleão, 2007). Para este artigo, em específico, selecionamos as duas questões anteriormente formuladas.

Este artigo descreve o referencial teórico em dois tópicos: o primeiro, analisa a relação entre gestão participativa e ação dos sindicatos; o segundo, aborda a relação entre terceirização e a legislação brasileira. Em seguida, os procedimentos metodológicos são apresentados tendo como base pesquisas realizadas pelo Grupo de Pesquisa do qual os autores são membros. O tópico seguinte, análise dos resultados, procura apresentar respostas para as duas questões que nortearam o trabalho. Ao final, há as considerações finais que resumem as principais conclusões.

\section{REFERENCIAL TEÓRICO}

\subsection{Gestão participativa e relação da empresa com os sindicatos}

De acordo com Heckscher (1996), o gerencialismo preconiza a participação do empregado no processo decisório. Ao se envolver com a organização, o empregado contribui para a consecução das metas empresariais (Heckscher, 1996; Furtado \& Carvalho Neto, 2007). A cultura do gerenciamento enriqueceu a linguagem e o discurso empresarial com os termos "trabalho em equipe", "participação" e "comprometimento", indicando um movimento, mesmo que seja representante de mera retórica (Heckscher, 1996).

Não há conceito único de gestão participativa. Ela é tratada na literatura por seus aspectos: participação na gestão (decisão e estratégia), no processo de trabalho (ideias e soluções), nos resultados e no lucro (Martins, 2000; Furtado \& Carvalho Neto, 2007), e na regulação de conflitos (Melo, 1984). A gestão participativa é uma estratégia gerencial utilizada pelas empresas para aumentar sua eficiência e eficácia (Heckscher, 1996; Furtado \& Carvalho Neto, 2007). Os objetivos da criação de espaços de troca de experiências e interação constante entre as pessoas podem ser o envolvimento e comprometimento dos trabalhadores com os objetivos da empresa, o aumento da produtividade, assim como a satisfação dos trabalhadores, a resolução de conflitos internos, e o exercício da cultura democrática pela democratização das decisões (Souza \& Guimarães, 1998; Storino, Dutra, Silva, Barros, 1999; Pastore, 1994; Mello, 2000; Melo, 1984; Oliveira, 1991). A participação pode acontecer pela presença maior dos empregados na cúpula, ou pela concessão de maior poder de decisão para a base (Pastore, 1994; Heckscher, 1996; Furtado \& Patrus-Pena, 2006).

Mudanças e as inovações com a implantação da gestão participativa no Brasil e em outros países apresentam antagonismos e motivaram críticas tanto de estudiosos quanto dos pesquisadores. Furtado e Carvalho Neto (2007) identificam duas correntes de críticos: os que apontam as limitações, mas enxergam os benefícios, e os que consideram que a participação só tem o objetivo de tornar os trabalhadores mais dóceis e menos organizados.

Os críticos argumentam que a efetividade dos esquemas participativos não foi comprovada, e os exercícios de participação não chegaram a representar, para as organizações, a democracia industrial como instrumento de decisão (Fleury, 1987; Storino et al, 1999). Na prática, o que se observou foi a criação de ambientes participativos que contribuíram com a redução de custos, a intensificação do ritmo de trabalho e do incremento de tarefas para os trabalhadores, sem que as relações de poder fossem alteradas no interior das empresas (Fleury, 1987; Oliveira, 1991; Bresciani, 1994). Muitos desses ambientes foram criados apenas como transferência de modelos de seus países de origem, sem a adaptação necessária. No Brasil, a participação foi tratada com excesso de simplismo, já que não houve conexão alguma com a legislação que regula as relações de trabalho, que, por sua vez, favorecem o paternalismo e o arbítrio gerencial. Além disso, os diversos grupos envolvidos nos esquemas participativos (gerentes, administradores, trabalhadores, 
consultores, supervisores, líderes sindicais) possuem valores e interesses diferentes que os norteiam, o que dificulta a aceitação, além de facilitar o aparecimento de resistência (Storch, 1987).

A gestão participativa também não encontra terreno fértil na cultura brasileira, marcada pelo patrimonialismo, personalismo e clientelismo (Guara \& Fleury, 2008). Não é irreal, portanto, que ela mascare a dominação por parte de uma minoria e que estimule o conservadorismo em um rótulo confortável (Garcia, 1998). Porém, a administração participativa é considerada fundamental na nova concepção de empresa competitiva. Ela pode facilitar o entendimento dos trabalhadores sobre os objetivos da empresa e, com isso, melhorar o comprometimento com a implementação de decisões, mesmo não tendo participado delas, pode aumentar a confiança do trabalhador na empresa, melhorar a comunicação e o relacionamento interno, gerar maior satisfação e o consequente maior rendimento (Mello, 2000). No nível individual, a participação pode representar ganhos na autoestima, autonomia, crescimento, desenvolvimento pessoal e profissional ao trabalhador (Furtado \& Carvalho Neto, 2007), embora nenhuma dessas vantagens tenha sido comprovada.

Uma peculiaridade dos sistemas participativos incentivados pelas empresas é que não abordam questões bastante relevantes para os trabalhadores, como a defesa dos salários e a manutenção dos empregos (Furtado \& Patrus-Pena, 2006). Além disso, a gestão participativa se afasta das práticas de relações de trabalho porque exclui os sindicatos, concentrando-se nos empregados próprios (Souza \& Guimarães, 1998).

Os empregados se congregam num sindicato de classe, a fim de se fortalecerem, e até mesmo, quando necessário, visando ao direito de entrar em greve, reunindo forças necessárias para pressionar o empregador a fazer acordos e certas concessões. Os empregadores têm também o direito de agir da mesma forma, tentando resistir às reivindicações ou à obtenção de concessões (Blanpain, 1998, p.103). Os sindicatos de empregados são os responsáveis por estabelecer com os empresários as negociações coletivas, que produzem uma série de direitos (as convenções ou os acordos coletivos, resultantes das negociações, têm força de lei durante sua vigência) que vão além da legislação já existente (Melo \& Carvalho Neto, 1998; Carvalho Neto, 2001). Indo além da legislação, esses "novos direitos" se coadunam com a ideia de responsabilidade social. Nesse sentido, uma empresa socialmente responsável, com relação a seu público interno, permite a atuação do sindicato no local de trabalho, que cria canais efetivos de comunicação, com transmissão de informações sobre condições de trabalho, dados financeiros e objetivos estratégicos que atinjam os trabalhadores.

A hipótese de que a gestão participativa forte enfraquece a relação da empresa com os sindicatos pode ser interpretada, por um lado, como uma estratégia de gestão empresarial interessada no afastamento do sindicato da negociação com os trabalhadores e, por outro, em uma crença verdadeira nas vantagens da participação dos empregados no processo de gestão. Por isso, parece ser importante investigar o tipo de participação dos empregados na gestão, pois participar do processo de execução de uma estratégia definida pela cúpula da empresa é diferente de participar do processo de escolha da estratégia.

\subsection{Terceirização e legislação brasileira}

A terceirização surgiu nos Estados Unidos, por volta de 1940, e foi muito aplicada durante a II Guerra. Com o fim do conflito mundial, evoluiu e transformou-se em uma técnica administrativa. No Brasil, a terceirização chegou pelas multinacionais, principalmente automotivas, que, desde os anos 1950 já implantavam, em menor grau, algum tipo de desverticalização estratégica. A desverticalização utilizada, principalmente pelas indústrias automotivas, buscava competitividade. Terceirizar algumas partes do processo produtivo a fornecedores externos constitui-se em uma opção viável para as empresas que buscam obter vantagem competitiva, por meio do foco em suas competências essenciais (Marchalek, Rebelato, Rodrigues, 2007; Queiroz, 1992; Amato Neto, 
1995; Leiria, 1995; Alvarez, 1996). A mão de obra terceirizada tornou-se comum na década de 1970, quando houve necessidade de reformulação das relações de trabalho, em razão da crise do petróleo. Inicialmente, a intenção era reduzir custos nas organizações e, em alguns países, era uma forma de se obter mais especialidade em relação ao trabalho que seria desenvolvido (Mattoso, 1995; Carvalho Neto, 2001; Piccinini, Oliveira, Rübenich, 2006).

Como pode ser visto na figura 1, a diferenciação entre terceirizados e empregados recai em três variáveis: a pessoalidade, a não-eventualidade e a subordinação, sendo esta última a que mais importa para a configuração ou não de uma relação de emprego. A onerosidade é comum tanto ao trabalhador contratado quanto ao terceirizado, mas com a diferença de que, na relação de emprego, a onerosidade é prevista na Consolidação das Leis do Trabalho, ao passo que, na relação com terceirizados, a onerosidade se dá conforme a prestação de serviços. Cabe observar que, em geral, a empresa terceirizada também segue a CLT para seus trabalhadores.

\begin{tabular}{|c|c|}
\hline Requisitos da relação de emprego & Requisitos da relação com terceirizados \\
\hline Pessoalidade & Impessoalidade \\
\hline Subordinação & Autonomia \\
\hline Não-eventualidade & Eventualidade \\
\hline Onerosidade prevista na CLT & Onerosidade conforme prestação de serviços \\
\hline
\end{tabular}

Figura 1: contradição entre empregado e terceirizado

Fonte: Elaborado por Gramiscelli, Y., Patrus-Pena, R. Assbú, L. B.(2009)

Cabe, então, investigar qual seria a melhor forma de uma empresa ser socialmente responsável, sem que haja subordinação, pessoalidade e não-eventualidade e sem correr riscos de aumento do passivo trabalhista. Por outro lado, se a empresa não oferece aos seus terceirizados as mesmas condições de trabalho e benefícios que oferece para seus empregados, a empresa obedece à lei, mas não parece ser socialmente responsável. É exatamente este dilema teórico que este artigo pretende trazer luz.

Assim, parece um dilema saber como uma empresa pode ser socialmente responsável sem que haja subordinação, habitualidade (não-eventualidade) e pessoalidade na prestação de serviços de seus terceiros, pessoas físicas, terceiros que possuem empresa constituída, mas que eles mesmos prestam o serviço ou mediante empresa interposta?

Observa-se que, para haver relação de emprego, é necessário haver os quatro requisitos impostos pela legislação: pessoalidade, subordinação, não-eventualidade e onerosidade. Para que seja reconhecido o vínculo de emprego, basta que haja pessoalidade e subordinação na prestação de serviços. Se um terceirizado reivindica o vínculo trabalhista na Justiça, ele pode gerar um passivo trabalhista para a empresa.

Um agravante para o dilema agora apresentado é o posicionamento do Instituto Ethos de Empresa e Responsabilidade Social, cujos indicadores foram a base das pesquisas realizadas pelo grupo de pesquisa do qual fazem parte os autores deste artigo. Desde 2005, o Instituto Ethos apresenta o relacionamento com os terceirizados como um indicador de responsabilidade social com o público interno. Para o Ethos, existem quatro estágios para o indicador. Se há terceirização de alguma atividade na empresa e esta deseja cumprir os quatro requisitos do indicador 14 do Ethos (2008), deverá “[...]monitorar o cumprimento da legislação e exigir que seus fornecedores pratiquem níveis de salários compatíveis com o mercado" (Ethos, 2008). Além disso, deverá "[...] oferecer ao terceirizado as mesmas condições de saúde e segurança, benefícios básicos (transporte, creche, alimentação, etc) que oferece para seus empregados" (Ethos, 2008). Ora, se isso acontecer, a empresa terceirizante estaria tratando seus terceirizados como trata seus empregados e, numa futura reclamação trabalhista, considerar-se-ia esta relação como vínculo de emprego entre a empresa terceirizante e o terceirizado, aumentando o passivo trabalhista da instituição. Parece, pois, 
que o indicador Ethos (2008) se mostra frágil para caracterizar a responsabilidade social de uma empresa em relação aos seus terceirizados.

Os estudos de Carroll (1979; 1991) apontaram a importância da lei como base da pirâmide da responsabilidade social. Ser responsável socialmente, em contradição com o que estabelece a lei, parece algo que contradiz não somente os pressupostos da responsabilidade social, mas a própria dinâmica de avaliação do Instituto Ethos que apresenta o cumprimento da lei como o primeiro estágio da responsabilidade social.

A pesquisa quantitativa, conduzida por Fernandes e Carvalho Neto (2005), com 513 presidentes, diretores e altos executivos de 179 empresas entre as 500 maiores e melhores do país, aponta que este problema ainda está por ser resolvido no Brasil. As empresas ainda falham nos aspectos relativos à gestão do desempenho e a remuneração por metas e resultados ainda está longe de se tornar realidade para os terceirizados, mesmo nos maiores conglomerados empresariais do Brasil. O mesmo ocorre com as práticas de gestão relativas à remuneração, à comunicação, ao poder de decisão na contratação, ao treinamento e ao desenvolvimento das pessoas, nas quais também é significativa a diferença entre terceirizados e empregados (Fernandes \& Carvalho Neto, 2005). Esse pior tratamento concedido aos terceirizados, concluem os autores, é um dos fatores que dificultam a contratação e retenção de profissionais com maior qualificação, motivação e comprometimento.

\section{PROCEDIMENTOS METODOLÓGICOS}

Esse artigo registra a revisão e a análise dos resultados de pesquisas realizadas por um núcleo de pesquisa de um Programa de Pós-Graduação em Administração de uma Instituição de Ensino Superior. Com o propósito de reunir estudos exploratórios realizados por meio de estudos de caso, buscou-se analisar todos os casos conjuntamente. Trata-se, portanto, de análise de dados secundários. As unidades escolhidas para análise foram as dissertações de Mestrado produzidas entre os anos de 2004 e 2008. Todas elas têm em comum o objetivo de investigar a responsabilidade social empresarial com o público interno (trabalhadores), tendo como base variáveis comuns, entre as quais a relação com os terceirizados, as relações com os sindicatos e a gestão participativa.

A estratégia de pesquisa adotada foi de natureza qualitativa, de caráter descritivo, uma vez que busca analisar duas questões:

1- Maiores níveis de gestão participativa na empresa enfraquecem as relações dos empregados com os sindicatos?

2- Como estabelecer uma responsabilidade social nas políticas de recursos humanos com terceirizados sem gerar risco de passivo trabalhista, considerando a legislação brasileira?

As pesquisas envolveram nove empresas de diferentes setores, que empregavam aproximadamente 17.300 pessoas, considerando apenas as unidades investigadas. A figura 2 apresenta resumidamente o universo das empresas pesquisadas no conjunto das dissertações analisadas.

Todas as empresas têm atuação no Brasil, sendo que a E6 envolve uma unidade brasileira (E6a) e uma unidade argentina (E6b) da mesma companhia, para efeito comparativo. Para a realização das pesquisas, foram distribuídos, no total, 3.787 questionários, com taxa de retorno, em média, de 67\%. Nos casos de E8, de E6a e E6b e de E9 foram realizados censos que contemplaram $100 \%$ dos funcionários das unidades pesquisadas. Os setores contemplados nas investigações foram os de alimentação, telecomunicações, engenharia e tecnologia, metalurgia, financeiro, siderurgia e utilidade pública. 


\begin{tabular}{|c|c|c|c|}
\hline Empresa & Autor & Setor/área da empresa & $\begin{array}{c}\text { Total de } \\
\text { respondentes } \\
\text { (válidos) }\end{array}$ \\
\hline E1 e E2 & Coelho (2004) & $\begin{array}{l}\text { INDÚSTRIA (E1: Alimentação) e } \\
\text { SERVIÇOS (E2: Telecomunicações) }\end{array}$ & 316 \\
\hline E3 & Oliveira (2005) & $\begin{array}{l}\text { INDÚSTRIA } \\
\text { Metalurgia }\end{array}$ & 189 \\
\hline $\mathrm{E} 4$ & Furtado (2006) & $\begin{array}{l}\text { SERVIÇOS } \\
\text { Engenharia e tecnologia }\end{array}$ & 197 \\
\hline E5 & Mattoni (2007) & $\begin{array}{l}\text { INDÚSTRIA } \\
\text { Metalurgia }\end{array}$ & 87 \\
\hline E6a e E6b & Santos (2007) & $\begin{array}{l}\text { SERVIÇOS } \\
\text { Financeiro }\end{array}$ & 351 \\
\hline E7 & Napoleão (2007) & $\begin{array}{l}\text { SERVIÇOS } \\
\text { Utilidade Pública }\end{array}$ & 247 \\
\hline E8 & Nagli (2008) & $\begin{array}{l}\text { INDÚSTRIA } \\
\text { Metalurgia }\end{array}$ & 616 \\
\hline E9 & Pereira (2008) & $\begin{array}{l}\text { INDÚSTRIA } \\
\text { Siderurgia }\end{array}$ & 265 \\
\hline
\end{tabular}

Figura 2: Relação das pesquisas sobre responsabilidade social empresarial com o público interno realizadas por um Núcleo de Pesquisa de uma Instituição do Ensino Superior.

Fonte: Elaborado pelos autores

As pesquisas anteriores caracterizaram-se como estudo de caso único, exceto nos casos E1 e E2 (caso múltiplo) e E6a e E6b (caso comparativo). Todos os pesquisadores utilizaram abordagem quantitativa, por questionários enviados ou aplicados, com o uso de técnicas qualitativas (entrevistas semiestruturadas, grupos focais ou análise documental) para complementar e dar mais consistência aos achados. O questionário de todas as pesquisas baseou-se nos Indicadores Ethos, cujas formulações foram transformadas em proposições. Em algumas pesquisas, essas proposições foram colocadas na forma interrogativa, com as seguintes opções de resposta: sim; não; não sei; prefiro não responder. Em outras pesquisas, o questionário mantinha a proposição da afirmativa e oferecia uma escala likert de cinco pontos com opções desde concordo totalmente até discordo totalmente. Como o teor dos questionários era o mesmo nas diferentes pesquisas, consideramos que os dados podem ser analisados em conjunto.

Todo esse material se constitui na fonte de dados para esta pesquisa. Representa, assim, o esforço de síntese de um grupo de pesquisa. Trabalhos como esse assumem relevância metodológica, na medida em que se valem de estudos de caso individuais inseridos em uma mesma abordagem de análise.

Trata-se, portanto, de um estudo de base secundária (as pesquisas realizadas e seus produtos, as dissertações), realizado de forma transversal, por meio do estudo comparativo de uma das variáveis (Relações com trabalhadores terceirizados), ou de um par de variáveis (Relações com sindicatos e gestão participativa).

\section{RESULTADOS}

\subsection{Maiores níveis de gestão participativa na empresa enfraquecem as relações dos empregados com os sindicatos?}

A análise aqui registrada concentra-se nos resultados das pesquisas da amostra selecionada em relação às variáveis "Relações com os sindicatos" e "Gestão participativa". Em primeiro lugar, procedeu-se a uma categorização das variáveis selecionadas em cada pesquisa, de acordo com 
resultados apresentados pelos questionários preenchidos pelos empregados das empresas e as entrevistas com gestores e presidentes de sindicatos. Para análise e comparação foram definidas as categorias fraca, forte e regular para classificar as duas variáveis, de acordo com critérios registrados na figura 3 , baseados na fundamentação teórica utilizada e no resultado das pesquisas analisadas.

Com base na análise da categorização, apresentada na figura 3, observou-se que a variável relações com sindicato, de um modo geral, não é positiva, uma vez que na metade das empresas apresentou-se fraca (E2, E3, E4, E6a e E6b). Em outras três empresas se apresentou regular (E1,E8 e E9) e em apenas duas (E5 e E7) pôde ser considerada como forte. Situação diferente pôde ser observada com a variável gestão participativa, já que em quatro casos foi classificada como forte (E5, E4, E6a e E6b), em três, como regular (E1, E3 e E9); e em outras três, como fraca (E2, E7 e $\mathrm{E} 8)$.

Após a categorização de cada uma das variáveis por empresa, com base nos dados de pesquisas, foram verificadas as diferenças, similaridades e características comuns aos dois tópicos nas empresas pesquisadas, incluindo o setor econômico ao qual a empresa está inserida, e o possível relacionamento entre as variáveis selecionadas.

\begin{tabular}{|c|c|c|c|}
\hline & FRACA & REGULAR & FORTE \\
\hline 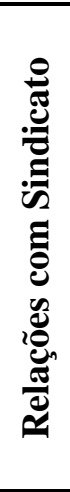 & $\begin{array}{l}\text { A empresa não possui } \\
\text { canal de diálogo ou } \\
\text { interação significativa } \\
\text { com o sindicato. }\end{array}$ & $\begin{array}{l}\text { A empresa procura manter algum } \\
\text { relacionamento com o sindicato, } \\
\text { mas coíbe, formal ou } \\
\text { informalmente, a participação dos } \\
\text { trabalhadores nas atividades } \\
\text { sindicais ou a atividade sindical no } \\
\text { local de trabalho, ou ainda há } \\
\text { desconhecimento generalizado e } \\
\text { discrepância entre a opinião de } \\
\text { gestores, empregados e } \\
\text { sindicalistas sobre o assunto. }\end{array}$ & $\begin{array}{l}\text { A empresa mantém } \\
\text { relacionamento com o } \\
\text { sindicato, não coíbe } \\
\text { participação dos trabalhadores } \\
\text { no sindicato e nem a atuação } \\
\text { do sindicato no local de } \\
\text { trabalho. Além disso, gestores, } \\
\text { empregados e sindicalistas } \\
\text { consideram bom o } \\
\text { relacionamento da empresa } \\
\text { com o sindicato. }\end{array}$ \\
\hline 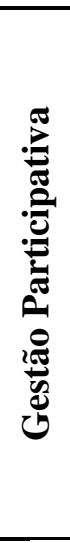 & $\begin{array}{l}\text { A empresa disponibiliza } \\
\text { informações econômico- } \\
\text { financeiras para os } \\
\text { empregados, mas não se } \\
\text { preocupa sobre o } \\
\text { esclarecimento delas para } \\
\text { os trabalhadores. } \\
\text { Gestores e empregados } \\
\text { desconhecem qualquer } \\
\text { programa de incentivo à } \\
\text { gestão participativa. }\end{array}$ & $\begin{array}{l}\text { A empresa possui programas de } \\
\text { sugestão para melhoria de } \\
\text { processos e participação de } \\
\text { empregados em comissões internas } \\
\text { de sistemas de qualidade, saúde, } \\
\text { segurança ou meio ambiente, mas } \\
\text { não envolve os empregados em } \\
\text { comitês de gestão ou decisões } \\
\text { estratégicas. }\end{array}$ & $\begin{array}{l}\text { Além de possuir programas de } \\
\text { sugestão, a empresa não } \\
\text { interfere na escolha dos } \\
\text { representantes dos empregados } \\
\text { para as comissões internas e } \\
\text { procura envolver os } \\
\text { empregados em comitês de } \\
\text { gestão ou administração. Os } \\
\text { gestores e os empregados } \\
\text { declaram que reconhecem a } \\
\text { gestão participativa na } \\
\text { empresa. }\end{array}$ \\
\hline
\end{tabular}

Figura 3: Critérios para categorização das variáveis selecionadas

Fonte: Elaborado por Castro, Pacheco e Patrus-Pena (2009).

Ao analisar a categorização das variáveis em relação ao setor da empresa, observou-se que no setor industrial há predominância da classificação regular, tanto para a variável relações com sindicato (E1, E8 e E9) quanto para a variável gestão participativa (E1, E3 e E9). Além disso, não se pôde destacar padrão de repetição ou antagonismo na classificação das variáveis que suscitasse atenção especial ou análise. O setor de serviços, por sua vez, apresentou-se especialmente singular. Em primeiro lugar, porque houve uma clara predominância de relações fracas com sindicatos (E2, 
E4, E6a e E6b) e gestões participativas fortes (E4, E6a e E6b). Além das opiniões mais assertivas em relação às duas variáveis, observou-se o antagonismo entre elas.

\begin{tabular}{|c|c|c|c|}
\hline \multirow{2}{*}{ Setor } & Empresa & $\begin{array}{c}\text { Relação com } \\
\text { sindicato } \\
\text { Regular }\end{array}$ & $\begin{array}{c}\text { Gestão } \\
\text { participativa }\end{array}$ \\
\hline \multirow{4}{*}{ Indústria } & E1 & Regular \\
\cline { 2 - 4 } & E3 & Fraca & Regular \\
\cline { 2 - 4 } & E5 & Forte & Forte \\
\cline { 2 - 4 } & E8 & Regular & Fraca \\
\cline { 2 - 4 } & E9 & Regular & Regular \\
\hline \multirow{4}{*}{ Serviços } & E2 & Fraca & Fraca \\
\cline { 2 - 4 } & E4 & Fraca & Forte \\
\cline { 2 - 4 } & E6a & Fraca & Forte \\
\cline { 2 - 4 } & E6b & Fraca & Forte \\
\cline { 2 - 4 } & E7 & Forte & Fraca \\
\hline
\end{tabular}

Figura 4: Categorização das variáveis selecionadas por setor das empresas pesquisadas Fonte: Castro et al (2009)

Em uma segunda etapa de análise, verificou-se, então, se a gestão participativa forte nas empresas pode estar ou não vinculada à fraca relação das empresas com os sindicatos dos trabalhadores. O objetivo da análise foi identificar se, a partir dos resultados obtidos nas pesquisas, é possível refutar a hipótese levantada por Heckscher (1996), quando descreve o gerencialismo, conceito que sugere que uma gestão participativa forte pode levar ao enfraquecimento da atuação dos sindicatos. Em quatro das oito dissertações produzidas pelo núcleo de pesquisa, que representa cinco das 10 empresas (E4, E5, E6a, E6b e E9), os resultados apresentam pistas que apontam para a relação entre as duas variáveis. Todavia, dessas cinco empresas, em apenas três (E4, E6a e E6b) os resultados possibilitam analisar a hipótese do gerencialismo de Heckscher (1996), já que possuem forte gestão participativa e, ao mesmo tempo, fraco relacionamento com os sindicatos.

Em E4, uma empresa do setor de engenharia e tecnologia, reconhecida pela responsabilidade social com o público interno e por uma gestão participativa forte em que os funcionários participam, de fato, da gestão do negócio, inclusive como acionistas, há indicativos que corroboram a hipótese do gerencialismo de Heckscher (Furtado, 2006). Nas unidades brasileira e argentina de um banco de investimentos internacional, representadas por E6a e E6b, encontraram-se resultados semelhantes. Os funcionários têm uma participação efetiva na gestão do negócio e há evidências de fraca atuação do sindicato, com grande desconhecimento dos empregados sobre o assunto. Embora contrarie o fato de a categoria dos bancários ter tradicionalmente forte representação sindical, trata-se de um banco de investimento, cujo corpo de empregados tem perfil diferente do de bancos comerciais de varejo (Santos, 2007).

Mesmo sem apresentar a relação entre as variáveis sugerida pela tese do gerencialismo, em E5 levantou-se a hipótese de que o enfraquecimento da atuação dos sindicatos pela implantação de uma gestão participativa só deve ser considerado para os altos níveis administrativos com curso superior e não para as categorias de base de uma empresa do setor metalúrgico. Essa percepção foi possível porque foram investigados separadamente os funcionários de base sindicalizados, que consideram a atuação sindical benéfica, e os funcionários administrativos, que, por sua vez a consideram prejudicial ao desempenho de suas atividades (Mattoni, 2007).

Em E9, uma empresa do setor de siderurgia, a possibilidade de relação entre as variáveis não se deu por nível de instrução ou função, mas em ordem inversa ao proposto na tese do gerencialismo, já que foi levantada a hipótese de que o sindicalismo forte e a boa relação que a empresa mantém com o sindicato poderiam provocar o enfraquecimento da gestão participativa (Pereira, 2008).

Os dados, enfim, permitiram supor que a hipótese do gerencialismo de Heckscher (1996) faz sentido apenas para o setor de serviços. A hipótese é refutada pelos dados da empresa E5, uma 
indústria, que apresentou gestão participativa forte e relação com o sindicato também forte. Entretanto, ao separar os dados dessa empresa entre os trabalhadores de chão de fábrica e os trabalhadores da área administrativa, observou-se que estes últimos apontaram seu relacionamento com o sindicato como fraco. Surge daí, uma hipótese nova, que não foi refutada pelos dados: trabalhadores de maior qualificação profissional, seja da área de serviços, seja da área industrial que observam maior gestão participativa na empresa também consideram que a relação com os sindicatos é fraca.

\subsection{Como estabelecer uma responsabilidade social nas políticas de recursos humanos com terceirizados sem gerar risco de passivo trabalhista, considerando a legislação brasileira?}

A análise dos dados coletados nas pesquisas é apresentada de acordo com os parâmetros dos quatro estágios do Indicador 14 (relação com trabalhadores terceirizados), do Instituto Ethos de Responsabilidade Social 2008, conforme especificado na metodologia. Cabe aqui ressaltar que apenas os estágios 3 e 4 configuram o item analisado como o de uma empresa como socialmente responsável, segundo o Ethos. Apenas quatro pesquisas (Santos (2007), Napoleão (2007), Nagli (2008), Pereira (2008) realizaram estudos com a variável "Relação com trabalhadores terceirizados". Essa variável foi acrescentada aos Indicadores Ethos somente a partir de $2006 \mathrm{em}$ diante.

Napoleão (2007) usou em sua pesquisa o indicador Ethos 2005. As três perguntas realizadas pela autora sobre o tema da terceirização se encaixam na pergunta do estágio 4 do indicador Ethos 2008, mas pelos resultados apurados nas entrevistas realizadas com gerentes e trabalhadores operacionais e administrativos, percebe-se que a empresa não se encaixa neste estágio. Os serviços terceirizados pela empresa pesquisada são, normalmente, de vigilância, limpeza e conservação, e em algumas situações envolvem pessoal mais qualificado, como consultores, engenheiros e outras funções necessárias para o desenvolvimento de projetos estabelecidos eventualmente. Também, um balanço social anual de 2005, confirma o pequeno percentual de funcionários terceirizados $(7,82 \%)$ que trabalha na empresa, o que pode ser um indício da grande quantidade de respondentes da pesquisa que não sabe dizer algo a respeito do que a empresa oferece aos trabalhadores terceirizados e aos efetivos.

A pesquisa feita por Pereira (2008) foi realizada em uma empresa que possui 350 empregados, sendo respondida por 265 pessoas. O número de funcionários terceirizados é relativamente baixo, são 19 (5,5\%), sendo que dois deles possuem entre 6 e 10 anos de casa, e os demais menos de 5 anos. Esta proporção de terceirizados encontra-se no patamar sugerido pelo Ethos (2008) - 20\%. Pelo índice de respostas consideradas positivas (sim e creio que sim), verificase que esta empresa corre risco de passivo trabalhista, pois fornece a seus trabalhadores terceirizados as mesmas condições que fornece aos seus empregados. No entanto, não houve variação nas respostas dadas pelos gerentes e tal pesquisa merece maior profundidade, seja quanto ao número de gerentes entrevistados, seja quanto aos terceiros diretamente entrevistados, para que se faça uma análise mais consistente dos resultados quanto ao risco de passivo trabalhista.

Na empresa 3 (Nagli, 2008), o questionário utilizado corresponde aos Indicadores Ethos 2008. O autor se recusou a estabelecer em que estágio a empresa se encontra, por considerar que a classificação por estágios não faz sentido. Para o autor, é possível que uma pergunta que representa o quarto estágio seja percebida positivamente sem que se note positivamente o enunciado que corresponde a um estágio anterior. Esse dado, revelado na variável sobre a relação com os terceirizados, impede o uso da classificação da responsabilidade em estágios na pesquisa realizada. Pela pesquisa, pode-se inferir que a empresa corre risco de passivo trabalhista, ainda que possa ser considerada socialmente responsável. 
Nas empresas 4.1 e 4.2 , a quantidade de trabalhadores terceirizados é muito pequena nas duas unidades pesquisadas. No Brasil (Empresa 4.1) de 409 funcionários, apenas 28 são terceirizados (7\%) e na Argentina (Empresa 4.2) de 187 funcionários, apenas sete são terceirizados (4\%). Tais números estão de acordo com os sugeridos pelo Indicador Ethos (2008), o qual sugere que a empresa deve possuir até, no máximo, $20 \%$ do número de empregados como terceiros. Apenas uma pergunta, entre as quatro que compõem a variável, foi abordada: "As condições de trabalho oferecidas aos funcionários terceirizados são as mesmas dos próprios funcionários?" Dos gerentes, 79,4\% responderam que sim. Dos empregados, $85,9 \%$ responderam que sim. Os dados apresentados na pesquisa, no entanto, são insuficientes para a análise mais detalhada sobre a RSE. Contudo, pelos índices de respostas positivas nessa pergunta, que, de algum modo, corresponde ao estágio 4 do Ethos (2008), nota-se que a empresa corre risco de passivo trabalhista se continuar a conceder aos seus terceirizados as mesmas condições que concede aos seus empregados.

\section{CONSIDERAÇÕES FINAIS}

Analisando a questão referente à associação entre gestão participativa forte na empresa e fraco relacionamento com os sindicatos, a pesquisa permitiu concluir que essa relação é possível apenas em empresas do setor de serviços. No setor industrial, os dados da empresa E5 refutaram essa hipótese. Essa constatação sugere três caminhos para indagações científicas, aqui apresentados como hipóteses para futuras pesquisas. A primeira possibilidade observada é que a relação descrita pelo gerencialismo tem significativa dependência com o setor econômico em que a empresa está inserida, já que só se manifestou em empresas do setor de serviços. Os resultados observados corroboram a afirmação de autores como Kochan e Wever (1991) e Heckscher (1996) de que os sindicatos têm dificuldades de atuar no setor de serviços.

A segunda possibilidade é a influência de outras variáveis na relação entre gestão participativa e relações com sindicato, como o nível salarial e a escolaridade. Os altos salários e níveis de escolaridade são pontos convergentes em E4, E6a e E6b. Daí poderíamos inferir uma hipótese curiosa: quanto maior o salário de uma categoria profissional, mais fraca é a relação da empresa com o sindicato. Se o sindicato tem como bandeira principal o aumento de salário, poderse-ia supor que a melhor forma de minimizar a atuação do sindicato é a empresa pagar altos salários a seus profissionais. $\mathrm{Na}$ área de serviços, observou-se gestão participativa forte e relação com sindicatos fraca em empresas que pagam bons salários.

Com relação à segunda questão norteadora deste artigo, observa-se que, para haver relação de emprego, é necessário haver os quatro requisitos impostos pela legislação: pessoalidade, subordinação, não-eventualidade e onerosidade. Basta que haja pessoalidade e subordinação para que seja reconhecido o vínculo de emprego com a empresa tomadora dos serviços, ou seja, para com a empresa que terceirizou. Assim, se há terceirização de alguma atividade na empresa e esta deseja cumprir os quatro requisitos sugeridos pelo Indicador 14 do Ethos (2008), para que ela cumpra o estágio 3 e 4, deverá oferecer ao terceirizado as mesmas condições de saúde e segurança, benefícios básicos (transporte, creche, alimentação etc.) que oferece para seus empregados. Ora, se isso acontecer, a empresa terceirizante estará tratando os terceirizados como trata seus empregados e, numa futura reclamação trabalhista, isso é visto como vínculo de emprego entre a empresa terceirizante e o terceirizado, o que aumenta o risco de passivo trabalhista da organização que terceirizou.

Conclui-se que o Indicador Ethos (2008) se mostra frágil para caracterizar a responsabilidade social de uma empresa em relação aos seus terceirizados. Como a pesquisa empírica demonstrou que, de fato, a percepção das condições oferecidas para os trabalhadores terceirizados supõem pessoalidade e subordinação dos terceiros, verifica-se que não se tem uma sugestão segura de como ser socialmente responsável sem se correr risco de passivo trabalhista. Em outras palavras, se a empresa quiser ser considerada socialmente responsável e seguir o indicador 14 do Ethos (2008) estará correndo sérios riscos de ver seu passivo trabalhista aumentar, pois estará, perante a 
legislação, primarizando e, não, terceirizando uma relação de trabalho. $O$ apontamento da fragilidade dos Indicadores Ethos não significa a defesa de piores condições para terceirizados. Significa a fragilidade de nossa legislação trabalhista ou a inconsistência jurídica do instituto da terceirização. Recomenda-se como pesquisa, no futuro, entrevistar pessoas que participaram da construção dos Indicadores Ethos, apresentando-lhes os dados dessa pesquisa e colhendo os dados acerca de seus posicionamentos.

Queremos crer que a investigação descritiva das duas questões norteadoras deste artigo representa um significativo avanço no desenvolvimento do tema da responsabilidade social com trabalhadores no Brasil. A passagem de pesquisas exploratórias para pesquisas descritivas indica o amadurecimento do grupo de pesquisa e a busca de verificação das hipóteses levantadas nas investigações exploratórias. Esperamos assim contribuir para o estudo das complexidades do estudo da RSE com os empregados, em particular no Brasil.

\section{REFERÊNCIAS}

Arruda, M. C. C., Navran, F. (2000). Indicadores de clima ético nas empresas. Revista de Administração de Empresas - RAE, São Paulo, 40 (3), 26-35.

Blanpain, R. (1998). O futuro do acordo coletivo. In: Ministério do Trabalho. Seminário Internacional Relações de Trabalho: aspectos jurídicos, sociais e econômicos. Brasília: Secretaria Executiva do Ministério do Trabalho.

Bresciani, L. P. (1994). Da resistência à contratação: tecnologia, trabalho e ação sindical no Brasil. Brasília: SESI-DN.

Carroll, A.B. (1979). A three-dimensional conceptual model of corporate performance. Academy of Management Review, 4, 497-505.

Carroll, A.B. (1991). The Pyramid of corporate social-responsibility: toward the moral management of organizational stakeholders. Business Horizons. 34 (4), 39-48.

Carvalho Neto, A. (2001). Relações de Trabalho e Negociação Coletiva na virada do milênio: estudo de quatro setores dinâmicos da economia brasileira. Petrópolis: Vozes.

Castro, P.P., Pacheco, L., Patrus-Pena, R. (2009, setembro) Relacionando variáveis da gestão de pessoas nas organizações: gestão participativa forte enfraquece as relações com os sindicatos? Anais do Encontro Nacional de Pós-graduação e Pesquisa em Administração, São Paulo, SP. Brasil, 33.

Clarkson, M. (1995). A stakeholder framework for analyzing and evaluating corporate social performance. Academy of Management Review, Mississippi, 20, 92-117.

Coelho, H. (2004). Gestão do público interno em empresas filiadas ao Instituto Ethos de Responsabilidade Social Empresarial: visão dos trabalhadores, dos gestores de pessoas e dos sindicalistas. (Dissertação de mestrado) - PUC Minas. Belo Horizonte, MG, Brasil.

Ethos, Instituto Ethos de Empresas e Responsabilidade Social. (2008). Indicadores Ethos de Responsabilidade Social Empresarial. São Paulo.

Fernandes, M. E., Carvalho Neto, A. (2005). Gestão dos múltiplos vínculos contratuais nas grandes empresas brasileiras; Revista de Administração de Empresas; Belo Horizonte: Edição Especial. 
Fleury, A. C. C. (1987). A organização do trabalho na indústria: Recolocando a questão nos anos 80. In: Fleury, M.T.L. \& Fischer, RM (coord). Processo e relações de trabalho no Brasil: movimento sindical, comissão de fábrica, gestão e participação, o modelo japonês de organização da produção no Brasil. São Paulo: Atlas.

França, M. A. (2005). Gestão da ética empresarial: análise da gestão da ética e responsabilidade social empresarial perante o público interno de uma empresa multinacional à luz de um marco referencial de ética nos negócios. (Dissertação de Mestrado) - PUC Minas. Belo Horizonte, MG, Brasil.

Frederick, W. C. (1994, agosto). From CSR1 to CSR2. Business and Society. 33 (2), 150-164.

Frederick, W. C. (1998, março). Moving to CSR4. What to pack for the trip. Business and Society, 37 (1), 40-59.

Furtado, R. A., Patrus-Pena, R. (2006). Empregados-acionistas: a visão de quem trabalha na Promon sobre as práticas de gestão participativa da empresa. Anais do Encontro Nacional de Pósgraduação e Pesquisa em Administração, Salvador, BA, Brasil.

Furtado, R. (2006), Responsabilidade Social Empresarial com o público interno: a percepção dos empregados da Promon. (Dissertação de mestrado) - PUC Minas. Belo Horizonte, MG, Brasil.

Furtado, R., Carvalho Neto, A.M. (2007). Uma contribuição para a construção de um modelo de análise da gestão participativa de empresas. Anais do Encontro Nacional de Pós-graduação $e$ Pesquisa em Administração, Natal, RN, Brasil.

Furtado, R., Patrus-Pena, R. (2007). Responsabilidade empresarial com o público interno: a percepção dos empregados da PROMON. RGSA - Revista de Gestão Social e Ambiental, 1, 39-57.

Garcia, F.C. (1998). A lei de ferro da oligarquia e o discurso da participação. Revista de Administração de Empresas; Rio de Janeiro: 28(2), 55-58.

Gramiscelli, Y., Patrus-Pena, R. Assbú, L. B. (2009). Gestão dos terceirizados: responsabilidade social ou risco de passivo trabalhista? Anais do Encontro Nacional de Pós-graduação e Pesquisa em Administração, São Paulo, SP, Brasil.

Guara, J. \& Fleury, S. (2008). Gestão participativa como instrumento de inclusão democrática: o caso dos comitês gestores de bairro do Programa Nova Baixada. Revista de Administração de Empresas, 48(3).

Heckscher, C. C. (1996). The new unionism: employee involvement in the changing corporation. Ithaca: ILR Press, Cornell University Press.

Kochan, T. \& Wever, K. R. (1991). American unions and the future of worker representation. In: Strauss, G., Gallagher, D.G.; Fiorito, J. The state of the unions. Madison: IRRA. Industrial Relations Research Association.

Martins, S.S. (2000). Participação nos lucros ou resultados: oportunidade ou desafio para o Movimento Sindical? Revista de Administração Contemporânea, 4 (3), 47-65.

Mattoni, L.A. M. (2007). Gestão do público interno e responsabilidade social: um estudo de caso em uma empresa signatária do Global Compact. (Dissertação de mestrado) - PUC Minas. Belo Horizonte, MG, Brasil. 
Mattoso, J. E. (1995). A desordem do trabalho. São Paulo: Página Aberta.

Mello, S.P.T. (2000). As influências do planejamento estratégico na gestão participativa da companhia carris Porto-alegrense. Anais do Encontro Nacional de Pós-graduação e Pesquisa em Administração.

Melo, M.C.O. (1984). Processos de participação como meios não-institucionalizados de regulação de conflitos. Revista de Administração de Empresas; Rio de Janeiro, v.24, n. 4, p-11-18.

Melo, M. C. O. L., Carvalho Neto, A. (1998). Negociação coletiva e relações de trabalho: o debate atual. São Paulo: ABET, 1998.

Nagli, L. S. D. (2008) Responsabilidade social empresarial com os trabalhadores e gestores de uma empresa metalurgica. (Dissertação de mestrado) - PUC Minas. Belo Horizonte, MG, Brasil.

Napoleão, R. S. (2007) A percepção dos gerentes e trabalhadores de uma grande empresa que se quer ser socialmente responsável sobre as ações direcionadas ao público interno. (Dissertação de mestrado) - PUC Minas. Belo Horizonte, MG, Brasil.

Oliveira, G. (1991). Democratização das relações de trabalho na empresa. Revista de Administração de Empresas; São Paulo, 31(4), 91-95.

Oliveira, T. J. E. (2005). Discurso e prática da responsabilidade social empresarial: um estudo da gestão do público interno: estudo de caso. (Dissertação de mestrado) - PUC Minas. Belo Horizonte, MG, Brasil.

Pastore, J. (1994). Flexibilização dos mercados de trabalho e contratação coletiva. São Paulo: LTR.

Patrus-Pena, R. Carvalho Neto, A., Teodosio, A. S., Coelho, H. M. Q., Fernandes, T., Dias, A. S. (2004). Discurso e prática da responsabilidade social: um estudo sobre a gestão do público interno em empresas signatárias do Global Compact. Belo Horizonte: Editora da PUC Minas. Research Summary.

Patrus-Pena, R. Coelho, H. M. Q., Carvalho Neto, A., Teodosio, A. S., Dias, A., Fernandes, T. (janmar 2007). Responsabilidade social empresarial e estratégia: um estudo sobre a gestão do público interno em duas empresas signatárias do Global Compact. Organizações \& Sociedade. 14 (40), Salvador, 81-98.

Pereira. A. R. (2008) Responsabilidade social empresarial com o público interno: percepção dos funcionários e gerentes em empresa de médio porte vencedora do Prêmio SESI de qualidade no trabalho. 153 f. (Dissertação de mestrado) - PUC Minas. Belo Horizonte, MG, Brasil.

Piccinini, V. C., Oliveira, S. R.; Rübenich, N. V. (2006). Formal, flexível ou informal? - reflexões sobre o trabalho no Brasil. In: Piccinini, V.C. et al. O Mosaico do trabalho na sociedade contemporânea. Porto Alegre, Editora da UFRGS.

Santos, C. T. B. (2007). A responsabilidade social empresarial de um banco de investimento americano sob a ótica de seu público interno no Brasil e na Argentina. 140f. (Dissertação de mestrado) - PUC Minas. Belo Horizonte, MG, Brasil. 
Souza, A. E. \& Guimarães, V.N. (1998) Gestão participativa na perspectiva de gerentes e trabalhadores: estudo comparativo de casos na indústria de plástico de Santa Catarina. Anais do Encontro Nacional de Pós-graduação e Pesquisa em Administração, 22

Storch, S. (1987). Discussão da participação dos trabalhadores na empresa. In: Fleury, M.T.L. \& Fischer, R.M. (coord). Processo e relações de trabalho no Brasil: movimento sindical, comissão de fábrica, gestão e participação, o modelo japonês de organização da produção no Brasil. São Paulo: Atlas.

Storino, G.R., Dutra, J.L.A., Silva; L., Barros, M.A.N. (1999). Racionalidade, liberdade, poder e efetividade: dimensões sistêmicas da decisão. Anais do Encontro Nacional de Pós-graduação $e$ Pesquisa em Administração, Foz do Iguaçu, PR., 23.

Tuma, F. (1999). Participação dos trabalhadores nos lucros ou resultados das empresas: incentive à eficiência ou substituição dos salários? São Paulo: LTr.

Wehling, C., Hernandez, A.G., Osland, J., Osland, A., Deller, J., Tanure, B., Carvalho Neto, A., Sairaj, A. (2009). European Journal of International Management, 3(2).

Wood, D. J. (1991, outubro). Corporate social performance revisited. Academy of Management Review, 16(4), 691-718.

Zibas, D.M.L. (1997) O reverso da medalha: os limites da administração industrial participativa. In Carleial, Liana e Valle, Rogério (Orgs). Reestruturação produtiva e mercado de trabalho no Brasil. São Paulo: Hucitec-Abet.

Data do recebimento do artigo: 14/10/2010

Data do aceite de publicação: 11/07/2012 